\title{
Bimetallic magnetic PtPd-nanoparticles as efficient catalyst for PAH removal from liquid media
}

\author{
A. F. S. Zanato ${ }^{1}$ V. C. Silva ${ }^{1}$ D. A. Lima ${ }^{1}$ M. J. Jacinto ${ }^{1}$
}

Received: 10 July 2017/ Accepted: 3 October 2017/Published online: 23 October 2017

(C) The Author(s) 2017. This article is an open access publication

\begin{abstract}
Monometallic Pd- and bimetallic PtPd-nanoparticles supported on a mesoporous magnetic magnetite@silica matrix resembling a core-shell structure $\left(\mathrm{Fe}_{3} \mathrm{O}_{4} @ \mathrm{mSiO}_{2}\right)$ have been fabricated. The material was characterized by transmission electron microscope (TEM), high-angle annular dark field-scanning transmission electron microscopy (HAADF-STEM), X-ray photoelectron spectra (XPS), energy dispersive spectroscopy (EDS) and inductively coupled plasma mass spectrometry (ICP-MS). The catalysts were applied in the removal of anthracene from liquid phase via catalytic hydrogenation. It was found that anthracene as a model compound could be completely converted into the partially hydrogenated species by the monometallic and bimetallic solids. However, during the recycling study the bimetallic material $\left(\mathrm{Fe}_{3} \mathrm{O}_{4} @ \mathrm{mSiO}_{2-}\right.$ PtPd-) showed an enhanced activity towards anthracene removal compared with the monometallic materials. A single portion of the PtPd-based catalyst can be used up to 11 times in the hydrogenation of anthracene under mild conditions ( $6 \mathrm{~atm}$ of $\mathrm{H}_{2}, 75^{\circ} \mathrm{C}, 20 \mathrm{~min}$ ). Thanks to the presence of a dense magnetic core, the catalysts were capable of responding to an applied external magnetic field and once the reaction was completed, catalyst/product separation was straightforward.
\end{abstract}

M. J. Jacinto

marcjrd@hotmail.com

1 Departamento de Química, Universidade Federal de Mato Grosso, Avenida Fernando Correa da Costa s/n-Cidade Universitária, Cuiabá, Mato Grosso 78060-900, Brazil
Keywords Anthracene - Bimetallic catalyst · Catalytic hydrogenation · Magnetic separation · Mesoporous silica

\section{Introduction}

PAHs (polycyclic aromatic hydrocarbons) constitute a large class of white or pale-yellow organic contaminants composed of multiple fused aromatic rings. These contaminants are known to have a low solubility in water and a high lipophilicity which provides these contaminants a reasonable solubility in most organic compounds. The intrinsic low mobility of PAHs is responsible for their tendency to be associated with particulate matter, soils and sediments. Most of PAHs are formed by a thermal decomposition process which leads to a subsequent recombination (pyrosynthesis) of organic molecules (WHO 2010; Rengarajan et al. 2015). The main sources of PAHs are anthropogenic emissions such as motor vehicle, fossil fuel burning, oil refining, asphalt production and industrial plants (Srogi 2007). PAHs are known to exhibit health hazards due to their carcinogenic and mutagenic properties (IARC 1983). PAHs are found in the air, oil and groundwater and are considered contaminants even in low concentrations (Yuan and Marshall 2005; Nador et al. 2010; Liao et al. 2011). Many different remediation technologies such as bioremediation, adsorption, and catalytic processes have been applied to either remove or chemically convert polycyclic aromatic hydrocarbons into less toxic compounds. Oxidation alternatives that include catalytic oxidation and bioremediation can result in the formation of reactive intermediates much more toxic than the parent PAH (Neff 2002, Zhang et al. 2013). Adsorption processes have been largely used to remove organic contaminants

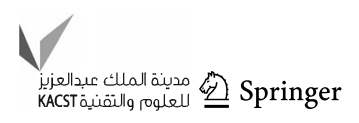


from water and wastewater. However, once the contaminant from the liquid media is removed the problem prevails as the organic pollutant is still present in the residual adsorbent.

Catalytic hydrogenation of PAHs is a remarkable strategy to remove these species from liquid media by converting PAHs into completely/partially hydrogenated counterparts which present much less environmental damage ( $\mathrm{Li}$ et al. 2015). It is also worth mentioning that partially/completely saturated species derived from PAHs are considered high-value compounds, and therefore catalytic hydrogenation of PAHs have both economical and environmental benefits ( $\mathrm{Li}$ et al. 2015). In a green perspective, the development of efficient hydrogenation catalysts for PAHs reduction which operate at mild reaction conditions is of great interest.

Many monometallic and bimetallic supported catalysts have been developed and used in a variety of industrial processes due to their unique catalytic property. Noble metal-based catalysts, especially, are an interesting alternative which is attributed to their unique high activity under mild reaction conditions (Wang et al. 2016; Valles et al. 2016; Zhang et al. 2016). The cost of using a noble metal-based catalyst such as $\mathrm{Rh}, \mathrm{Pt}$, Ir and $\mathrm{Pd}$ can be compensated by using low temperatures and $\mathrm{H}_{2}$ pressures (Valles et al. 2016). Catalyst selectivity, durability and activity can be improved by combining two different metals in a bimetallic composite. Dash et al. synthesized monometallic and bimetallic PdAu-based nanoparticles stabilized in ionic liquids and studied their activity in the hydrogenation of $\mathrm{C}=\mathrm{C}$ bonds. It was found that both activity and selectivity for the model reactions could be tuned by varying the composition of the bimetallic nanoparticles, and maximum activities were obtained at 1:3 Au:Pd ratios (Dash et al. 2008). Villa et al. (2015) also showed that the presence of bimetallic AuRu-phase on activated carbon led to an improved catalytic durability in the levulinic acid hydrogenation, and a single portion of the catalyst could be used in six successive runs.

In the last decade mesoporous materials have attracted a great deal of interest due to their interesting chemical and physical properties such as large surface area, void pore volume and controlled porosity. Application of this class of materials includes energy storage, drug delivery, electronic devices and catalysis (Atchudan and Pandurangan 2012). Compared to ordinary solids mesoporous catalytic supports have a larger concentration of active sites, and because of their porous nature adsorption and diffusion of reactants and molecules are facilitated (Fei et al. 2016). Mesoporous catalytic supports have been extensively used as carriers for the catalytically active phase in liquid- and gas-phase catalysis. Many fine chemicals are usually complex multifunctional molecules with high boiling points and limited thermal stability, and thus reactions in the liquid phase and mild temperature are often required (Ziolek 2004). However, catalyst separation from the final product in liquid-phase reactions can be problematic due to the interaction between the catalyst and the liquid medium containing the substrate and products (Jacinto et al. 2008). One useful strategy to overcome catalyst/ product separation drawbacks in those systems is the design of catalyst carriers with inherent magnetic properties. By using a magnetic separable support once the reaction is completed the catalyst can be completely isolated from the liquid media by applying a localized magnetic field. Recently, we reported the development of a platinum-supported mesoporous silica catalyst that comprised magnetite cores coated with mesoporous silica containing platinum nanoparticles $(2-4 \mathrm{~nm})$ on its surface (Jacinto et al. 2016). The catalyst was applied in hydrogenation of PAHs and exhibited promising activity under very mild reducing conditions. The inherent superparamagnetic property of the solid $\left(6.66 \mathrm{emu}^{-1}\right)$ enabled an on-demand magnetization by applying an external magnetic field, and a fast and efficient catalyst isolation from the liquid media was achieved (Jacinto et al. 2016). The prominent results motivated us to develop active bimetallic PdPt nanoparticles deposited on the magnetic mesoporous silica support for PAHs removal. When compared to Pd- and Pt-monometallic catalysts, the lifetime of the bimetallic material for anthracene removal was increased by 2.2 and 1.8 times, respectively. It was also found that the combination of two monometallic phases changed the product selectivity significantly and a higher selectivity toward the formation of partially hydrogenated DHA compound was achieved. We believe that important features attained in the development of the PdPt-bimetallic catalyst such as higher catalyst durability, facile and straightforward catalyst separation and controlled selectivity are of great interest when designing new catalysts for cleaner and more efficient technologies.

\section{Materials and methods}

\section{Catalyst preparation}

$12 \mathrm{~nm} \mathrm{Fe}_{3} \mathrm{O}_{4}$ nanoparticles were obtained according to the method developed by Park et al. (2004). Detailed procedure for the formation of silica-coated magnetite nanoparticles is provided elsewhere (Jacinto et al. 2016). Briefly, $8 \mathrm{~mL}$ of oleic acid-stabilized $\mathrm{Fe}_{3} \mathrm{O}_{4}$ nanoparticles dispersed in hexane (9.6 $\mathrm{mg} \mathrm{L}^{-1}$ ) was emulsified with $80 \mathrm{~mL}$ of distilled water using a mechanical stirrer (4500 rpm), and then transferred to $720 \mathrm{~mL}$ of an aqueous solution containing $\mathrm{NaOH}(13 \mathrm{mM})$, TEOS $(49 \mathrm{mM})$, ethyl acetate $(0.68 \mathrm{M})$ and APTES 
$(0.49 \mathrm{mM})$. The solution was stirred for $3 \mathrm{~h}$ at $70{ }^{\circ} \mathrm{C}$. The resulting material consisting of magnetite nanoparticles coated with a mesoporous silica layer $\left(\mathrm{Fe}_{3} \mathrm{O}_{4} @ \mathrm{mSiO}_{2}\right)$ was used then as a support to obtain Pd-, Pt- and PtPd-@ $\mathrm{SiO}_{2} @$ $\mathrm{Fe}_{3} \mathrm{O}_{4}$ catalysts. For this purpose, $500 \mathrm{mg}$ of the catalyst support $\left(\mathrm{Fe}_{3} \mathrm{O}_{4} @ \mathrm{mSiO}_{2}\right)$ was added to a beaker containing $5 \mathrm{~mL}$ of a $2.5 \mathrm{mg} \mathrm{mL}^{-1} \mathrm{~K}_{2} \mathrm{PtCl}_{4}$ solution and $5 \mathrm{~mL}$ of a $5 \mathrm{mg} \mathrm{mL}^{-1} \mathrm{Pd}\left(\mathrm{NO}_{3}\right)_{2}$ solution. The mixture was magnetically stirred for $2 \mathrm{~h}$ at $25^{\circ} \mathrm{C}$ and the solid containing $\mathrm{Pd}^{2+}$ and $\mathrm{Pt}^{3+}$ ions was isolated by placing a small magnet $(4000 \mathrm{G})$ on the beaker wall. The material dubbed $\mathrm{Fe}_{3} \mathrm{O}_{4} @ \mathrm{SiO}_{2} @ \mathrm{Pt}^{3+-}$ $\mathrm{Pd}^{2+}$ was then dried for $8 \mathrm{~h}$ at $80^{\circ} \mathrm{C}$. Bimetallic $\mathrm{PdPt}$ nanoparticles embedded on the mesoporous magnetic matrix was obtained by reduction of $\mathrm{Pt}^{3+} \mathrm{Pd}^{2+}$ species using $\mathrm{H}_{2}$ as the reducing agent. In this step, $500 \mathrm{mg}$ of the catalyst precursor $\left(\mathrm{Fe}_{3} \mathrm{O}_{4} @ \mathrm{mSiO}_{2} @ \mathrm{Pt}^{3+} \mathrm{Pd}^{2+}\right)$ and $5 \mathrm{~mL}$ of cyclohexene were added in a modified Fischer-Porter glass bottle and pressurized at 6 atm with $\mathrm{H}_{2}$ connected to a gas supply at $16 \mathrm{~atm}$ delivering $\mathrm{H}_{2}(99.998 \%$ purity) at a constant pressure (6 atm, $\left.75^{\circ} \mathrm{C}\right)$ to the reactor vessel. The formation of bimetallic nanoparticles grafted on the mesoporous support could be monitored by the pressure gas drop in the gas supply manometer as a result of $\mathrm{H}_{2}$ consumption during the hydrogenation of cyclohexene to cyclohexane promoted by preformed PtPd nanoparticles. After $30 \mathrm{~min}$, the $\mathrm{H}_{2}$ pressure was released, the catalyst was collected magnetically using a permanent $\mathrm{Nd}$ magnet, and washed twice with water and ethanol to remove $\mathrm{Cl}^{-1}$ ions. Finally, the material was dried at $80{ }^{\circ} \mathrm{C}$ for $8 \mathrm{~h}$. A very similar protocol was used to obtain monometallic monometallic Pd-catalyst.

\section{Characterization}

The bimetallic catalyst $\left(\mathrm{Fe}_{3} \mathrm{O}_{4} @ \mathrm{mSiO}_{2} @ \mathrm{PtPd}-\right)$ and monometallic Pd counterpart $\left(\mathrm{Fe}_{3} \mathrm{O}_{4} @ \mathrm{mSiO}_{2} @ \mathrm{Pd}\right)$ were characterized by X-ray photoelectron spectroscopy at a pressure lower than $10^{-7} \mathrm{~Pa}$ using a commercial spectrometer (UNI-SPECS UVH System, Berlin, Germany). The $\mathrm{MgKa}$ line was used $(\mathrm{hm}=1253.6 \mathrm{eV})$, and the analyzer pass energy was set to $10 \mathrm{eV}$. The binding energy scale of the spectra was corrected using $\mathrm{C} 1 \mathrm{~s}$ hydrocarbon component of the fixed value of $285.0 \mathrm{eV}$. The spectra were fitted without placing constraints using multiple Voigt profiles. The width at half maximum (FWHM) varied between 1.2 and $2.1 \mathrm{eV}$, and the accuracy of the peak positions was $\pm 0.1 \mathrm{eV}$. High-angle annular dark field scanning transmission electron microscopy (HAADFSTEM) images were obtained using a transmission electron microscope (FEI Tecnai F20 HRTEM) operating at $200 \mathrm{kV}$. The samples were prepared by suspending $\sim 1 \mathrm{mg}$ in $5 \mathrm{~mL}$ of water and placing a drop of the solution onto a copper grid with amorphous carbon film. Elemental compositions of specific sample regions were analyzed by an energy-dispersive spectrometer (EDS) connected to the STEM microscope. The Pd and Pt amount in each catalyst was determined by ICP-AES (Spectro, Genesis SOP). The liquid products obtained in the hydrogenation reactions were analyzed by GC-MS equipped with a $30 \mathrm{~m}$ capillary column with a dimethylpolysiloxane stationary phase using the following parameters: initial temperature $100{ }^{\circ} \mathrm{C}, 5 \mathrm{~min}$, ramp $15^{\circ} \mathrm{C} \mathrm{min}^{-1}$, final temperature $250{ }^{\circ} \mathrm{C}$, final time $30 \mathrm{~min}$, injector and detector temperature $250{ }^{\circ} \mathrm{C}$. UV-Vis experiments were performed in a Femto-Cirrus $80 \mathrm{MB}$ UV spectrophotometer using a quartz cuvette with $10-\mathrm{mm}$ path length $(3.5 \mathrm{~mL})$.

\section{Catalytic studies}

Hydrogenation experiments using mono- and bimetallic catalysts were performed in a modified Fischer-Porter glass reactor pressurized at the desired $\mathrm{H}_{2}$ pressure. The pressure in the glass reactor was kept constant by leaving it open to the hydrogen supply cylinder controlled by a manometer regulator. The temperature was maintained constant by immersing the reactor in a beaker containing silicon oil on a hot-stirring plate connected to a digital temperature controller. The effect of different reaction parameters such as $\mathrm{H}_{2}$ pressure, reaction time was also evaluated. In a typical experiment the system was purged twice with $\mathrm{H}_{2}$ to remove the air trapped in the reactor, and a targeted catalyst amount and substrate dissolved in ethyl acetate (24 ppm) were introduced into the reactor containing a 1-cm magnetic bar. The liquid mixture was magnetically stirred with rotation speed of $400 \mathrm{rpm}$ throughout the entire course of the reaction. After the established reaction time was over the $\mathrm{H}_{2}$ pressure was released, the reactor was lifted 10-15 cm out of the silicon bath and an external $\mathrm{Nd}$ magnet was placed on the reactor wall so that the catalyst could be magnetically isolated from the liquid phase. Finally, the liquid portion was isolated by inserting a syringe connected to an SGE needle $(20 \mathrm{~cm})$. The substrate conversion and products were analyzed by GC-MS and UV-VIS as described in "Catalytic tests". The recyclability and lifetime of $\mathrm{PtPd}$ - and $\mathrm{Pd}$ $@ \mathrm{SiO}_{2} @ \mathrm{Fe}_{3} \mathrm{O}_{4}$ was examined in different successive runs of anthracene hydrogenation under the following established conditions: 6 atm of $\mathrm{H}_{2}, 75^{\circ} \mathrm{C}, 20 \mathrm{~min}$. Catalyst separation after each hydrogenation experiment was also carried out using a small magnet placed on the reactor glass wall.

\section{Results and discussion}

\section{Catalyst characterization}

Both the support $\mathrm{Fe}_{3} \mathrm{O}_{4} @ \mathrm{mSiO}_{2}$ and the monometallic $\mathrm{Pt}$ catalyst $\left(\mathrm{Fe}_{3} \mathrm{O}_{4} @ \mathrm{mSiO}_{2} \mathrm{Pt}\right)$ have been previously 


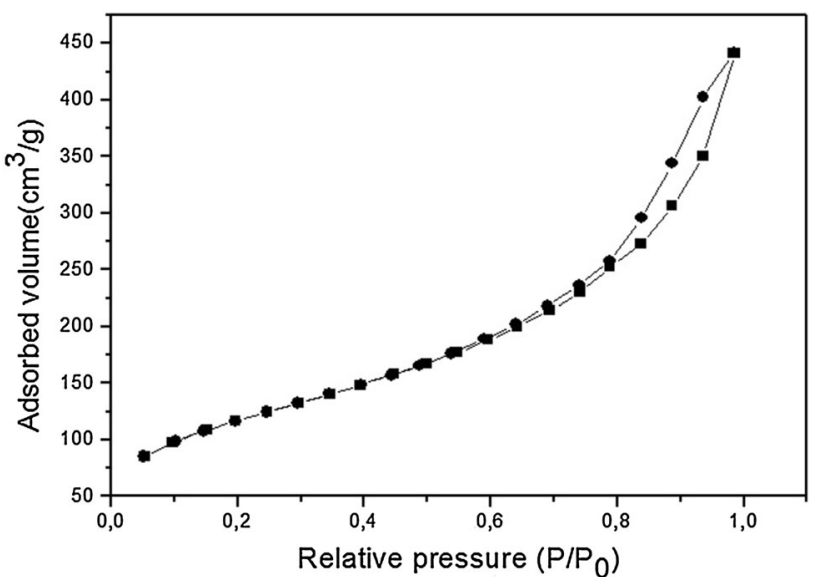

Fig. 1 Nitrogen adsorption-desorption isotherm for $\mathrm{Fe}_{3} \mathrm{O}_{4} @ \mathrm{mSiO}_{2}$

characterized by HRTEM, IR, EDS, ICP-AES, and XPS. The support is composed of magnetite nanoparticles $(\sim 12 \mathrm{~nm})$ coated with mesoporous silica (pore size $\sim 4 \mathrm{~nm}), \mathrm{Ms}=6.66 \mathrm{emu} \mathrm{g}^{-1}$ and Pt loading of $1.6 \mathrm{wt} \%$ (Jacinto et al. 2016). Figure 1 shows that the nitrogen adsorption-desorption isotherm for the support exhibits a typical IV type isotherm with $\mathrm{H}_{1}$ hysteresis loop $\left(p / p_{0}<1\right)$ corresponding to mesoporous material $(1.5-100 \mathrm{~nm})$ (Gregg and Sing 1982).
STEM analysis of the PtPd-nanoparticles synthesized by the reduction of metal salts on the magnetic mesoporous support is shown in Fig. 2. Despite the presence of some agglomerates, the particles are well dispersed on the walls of the mesoporous silica matrix and mean diameter of $\sim 1.2 \mathrm{~nm}$ is found for the bimetallic PtPd-particles according to Fig. 2a. X-ray analysis of red box area of TEM image (Fig. 2b) is given in Fig. 2c. The results show the presence of both Pt and Pd which suggests the presence of a random alloy structure. The metal topological distribution of two monometallic phases may be classified as random alloy structure $(\mathrm{AB})$, core-shell type-1 (A@B) and core-shell type-2 (B@A). Since the Z-contrast images is proportional to the atomic number of the bimetallic species. It is very hard to distinguish Pt from Pd because of their similar atomic weight when compared to the other elements present in the composite $(\mathrm{Si}, \mathrm{Fe}, \mathrm{O})$. In order to confirm the presence of a random alloy structure elemental mapping images of $\mathrm{Pt}$ and $\mathrm{Pd}$ for a single region were obtained separately.

The HAADF-STEM image of PtPd-nanoparticles containing the elemental analysis scanning is shown in Fig. 3. Separate chemical mappings of $\mathrm{Pt}$ and $\mathrm{Pd}$ are shown in Fig. 3b, c, respectively. The presence of individual
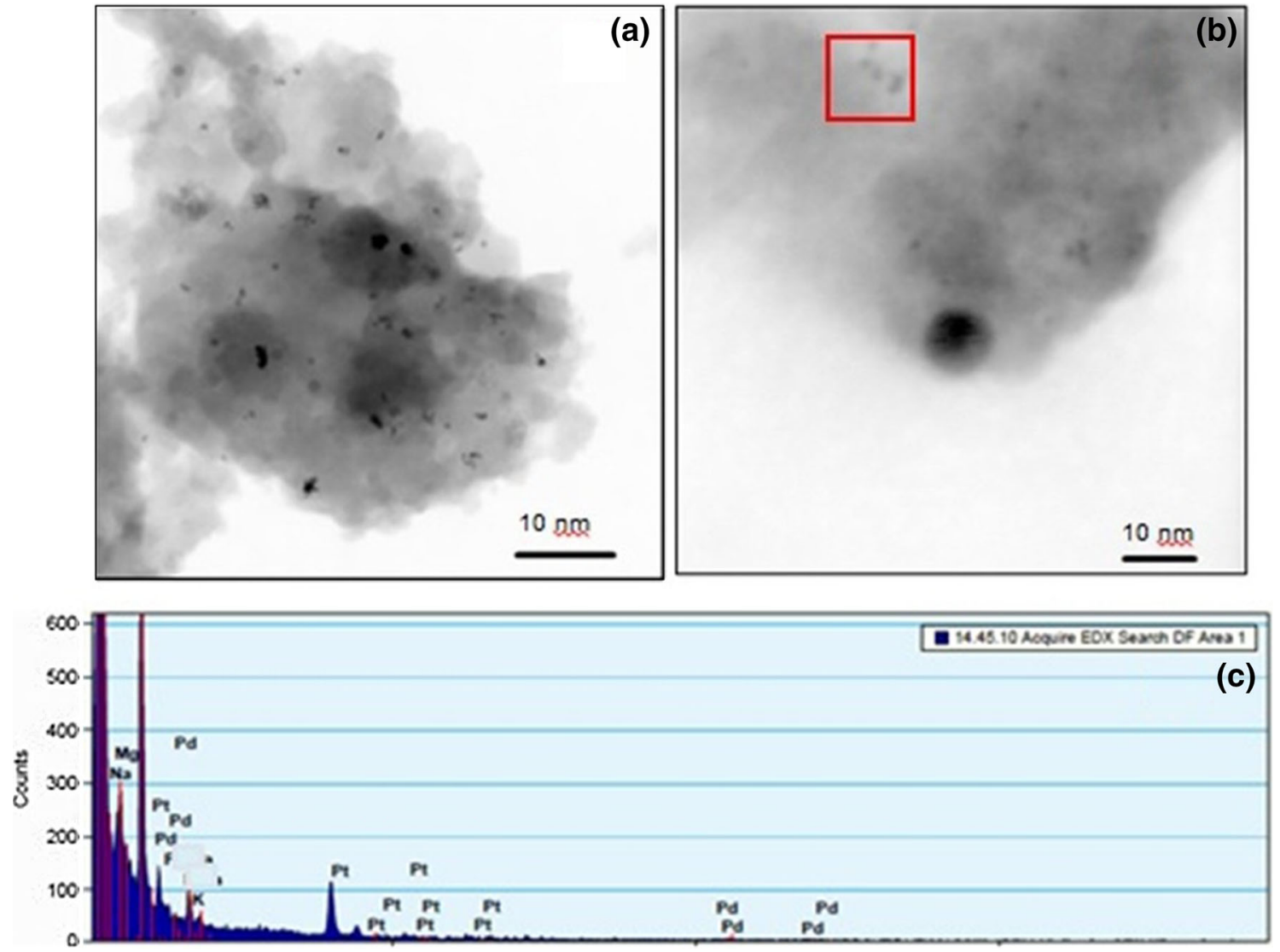

Fig. 2 TEM image of $\mathrm{Fe}_{3} \mathrm{O}_{4} @ \mathrm{mSiO}_{2} \mathrm{PtPd}-(\mathbf{a}, \mathbf{b})$ and EDS analysis of the red box area (c) 

micrography for the material $\mathrm{Fe}_{3} \mathrm{O}_{4} @ \mathrm{mSiO}_{2} @ \mathrm{PtPd} . \mathbf{b}$, c HAADF-STEM micrography containing elemental mapping images for Pt and Pd, respectively
Fig. 3 a HAADF-STEM
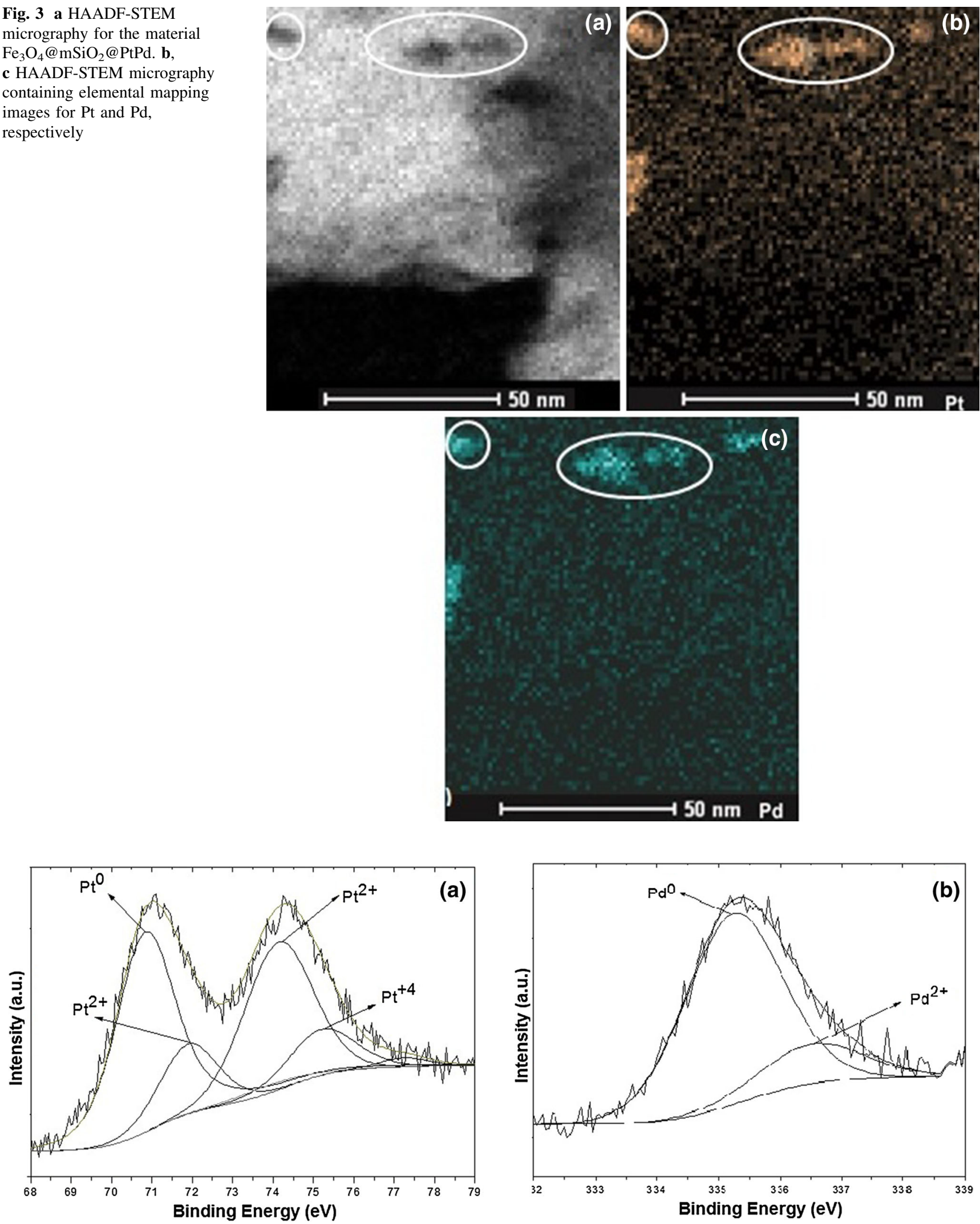

Fig. 4 XPS spectra measured on Pt (a) and Pd (b) 

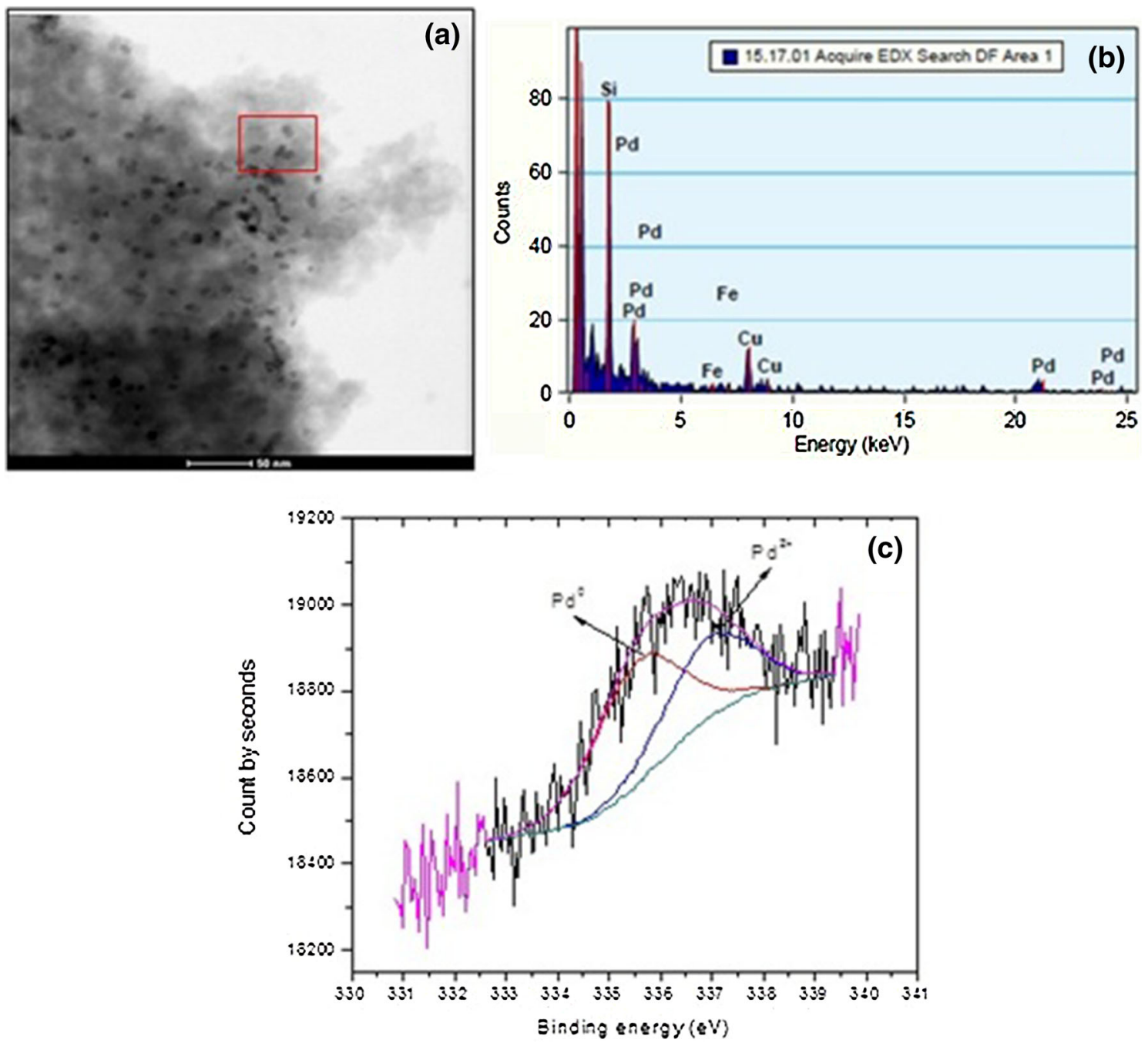

Fig. 5 a TEM image for $\mathrm{Fe}_{3} \mathrm{O}_{4} @ \mathrm{mSiO}_{2} \mathrm{Pd}$; b EDS analysis of red box area shown in a; $\mathbf{c} \mathrm{Pd} 3 \mathrm{~d}$ XPS spectra measured on Pd

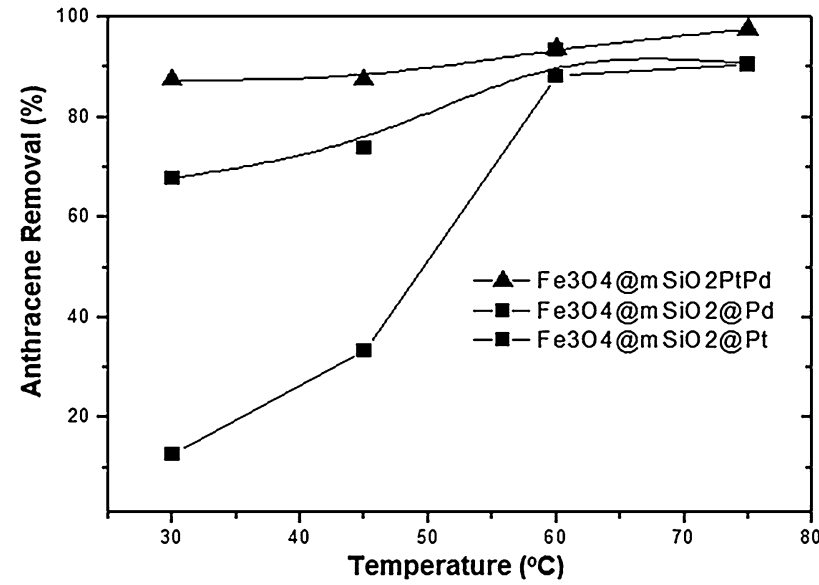

Fig. 6 Anthracene removal via catalytic hydrogenation as a function of temperature for $\mathrm{Fe}_{3} \mathrm{O}_{4} @ \mathrm{mSiO}_{2} \mathrm{PtPd}-, \mathrm{Fe}_{3} \mathrm{O}_{4} @ \mathrm{mSiO}_{2} \mathrm{Pd}$ and $\mathrm{Fe}_{3-}$ $\mathrm{O}_{4} @ \mathrm{mSiO}_{2} \mathrm{Pt}$. Reaction conditions: $10 \mathrm{mg}$ of catalyst, $5 \mathrm{~mL}$ of anthracene-ethyl acetate solution $(24 \mathrm{ppm})$, pressure of $\mathrm{H}_{2} 6 \mathrm{~atm}$, time $20 \mathrm{~min}$

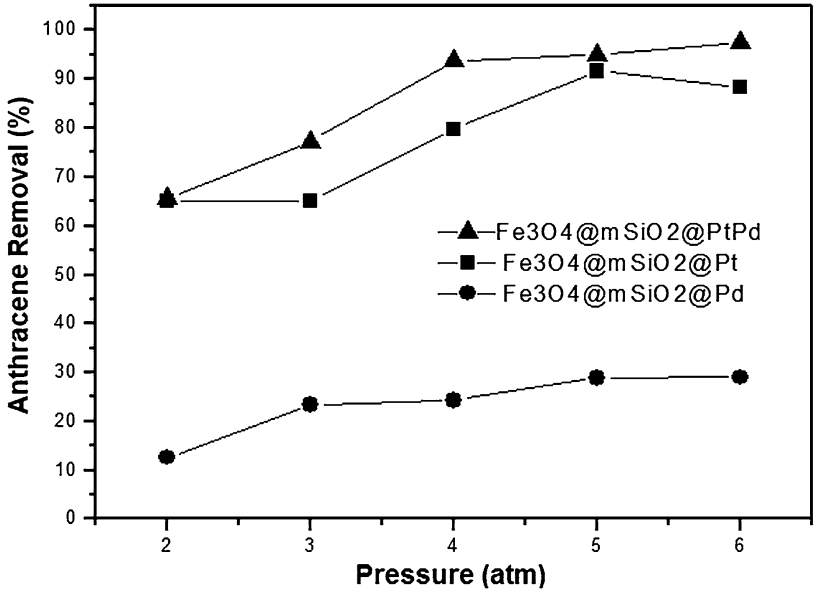

Fig. 7 Anthracene removal by catalytic hydrogenation as a function of pressure for $\mathrm{Fe}_{3} \mathrm{O}_{4} @ \mathrm{mSiO}_{2} \mathrm{PtPd}-, \mathrm{Fe}_{3} \mathrm{O}_{4} @ \mathrm{mSiO}_{2} \mathrm{Pd}$ and $\mathrm{Fe}_{3} \mathrm{O}_{4} @$ $\mathrm{mSiO}_{2} \mathrm{Pt}$. Reaction conditions: $10 \mathrm{mg}$ of catalyst, $5 \mathrm{~mL}$ of anthracene-ethyl acetate solution ( $24 \mathrm{ppm})$, temperature $30{ }^{\circ} \mathrm{C}$, time $30 \mathrm{~min}$ 

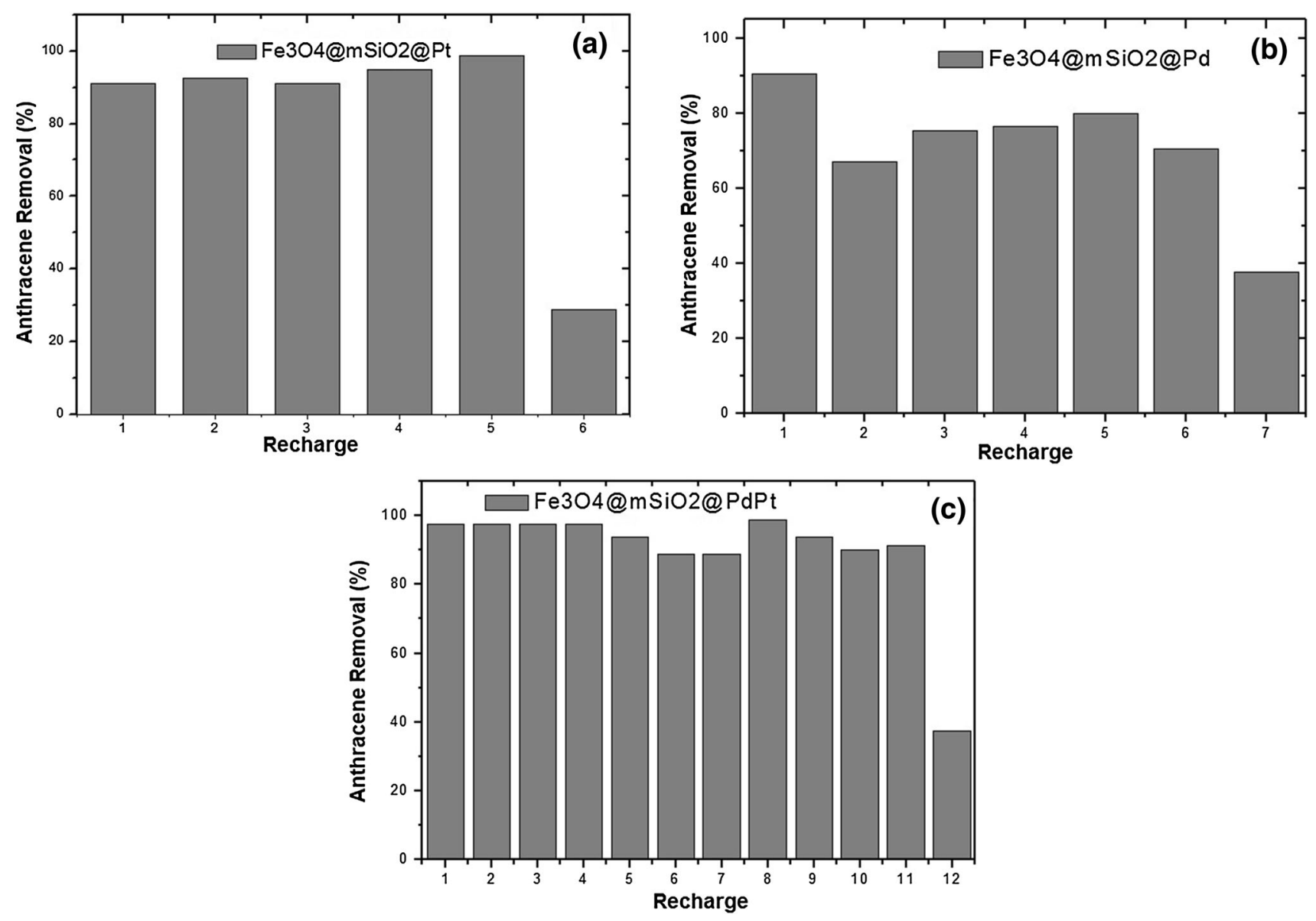

Fig. 8 Catalyst recycling for anthracene removal. Reaction conditions: $10 \mathrm{mg}$ of catalyst, $5 \mathrm{~mL}$ anthracene-ethyl acetate solution (24 ppm), $75^{\circ} \mathrm{C}, 6 \mathrm{~atm}$ of $\mathrm{H}_{2}, 20 \mathrm{~min}$

elemental contrasts (separate Pt and Pd phases) which would suggest a core-shell composition is not observed. This result confirms the formation of random PtPd-alloy structure in the mesoporous magnetic support phase (Fig. 3a). ICP-AES analysis shows that the quantification of metal loading for PtPd is 0.49 and $0.65 \mathrm{wt} \%$ for Pt and $\mathrm{Pd}$, respectively, which makes up to a total of $1.14 \mathrm{wt} \%$ of catalytic active metal species in the support.

Figure 4a shows the surface analysis obtained by XPS technique for the material $\mathrm{Fe}_{3} \mathrm{O}_{4} @ \mathrm{mSiO}_{2} @ \mathrm{PtPd}$. The bimetallic phase is composed of four main components for Pt. The first peak at $70.8 \mathrm{eV}$ can be attributed to zerovalent Pt. The remaining higher energy peaks at $72,74.2$ and $75.2 \mathrm{eV}$ are in agreement with the presence of oxidized $\mathrm{Pt}$ species $\left(\mathrm{Pt}^{2+}\right.$ and $\left.\mathrm{Pt}^{4+}\right)$ (Wagner et al. 1979). Pd species energy (Fig. 4b) suggests the presence of $\operatorname{Pd}(0)$ at $335.3 \mathrm{eV}$ and $\mathrm{Pd}^{2+}$ at $336.3 \mathrm{eV}$ (Wagner et al. 1979). The presence of noble oxidized $\left(\mathrm{Pd}^{2+}\right.$ and $\left.\mathrm{Pt}^{2+}\right)$ suggests that the reduction process resulted in a partial reduction of metal ions during the fabrication of the composite which is probably due to the formation of highly stable APTESPd(II) and APTES-Pt(II) complexes (6a).
Figure 5 shows a typical STEM image of the monometallic Pd catalyst $\left(\mathrm{Fe}_{3} \mathrm{O}_{4} @ \mathrm{mSiO}_{2} @ \mathrm{Pd}\right)$. The presence of Pd nanoparticles decorating the support surface is confirmed by EDS analysis of a red box containing a few Pd nanoparticles. Based on Fig. 5a the Pd nanoparticles have an estimated size of $\sim 6.4 \mathrm{~nm}$ and despite the formation of some agglomerates the particles are in general well-dispersed. XPS analysis for the Pd monometallic catalyst was also carried out to obtain a surface profile of the material. Figure $5 \mathrm{c}$ shows two components at 335.8 and $337.1 \mathrm{eV}$ which correspond to $\mathrm{Pd}(0)$ and $\mathrm{Pd}^{2+}$, respectively. The presence of oxidized metal ions is probably due to the formation of APTES-Pd(II) which is a lot more resistant to reduction by $\mathrm{H}_{2}$ compared to free metal ions. The amount of Pd determined by ICP-AES for the monometallic Pd catalyst is $1.02 \mathrm{wt} \%$.

\section{Catalytic tests}

The PtPd-, Pt- and Pd-catalysts were initially tested in the removal of anthracene from liquid media via catalytic hydrogenation at different temperatures. The conversions 


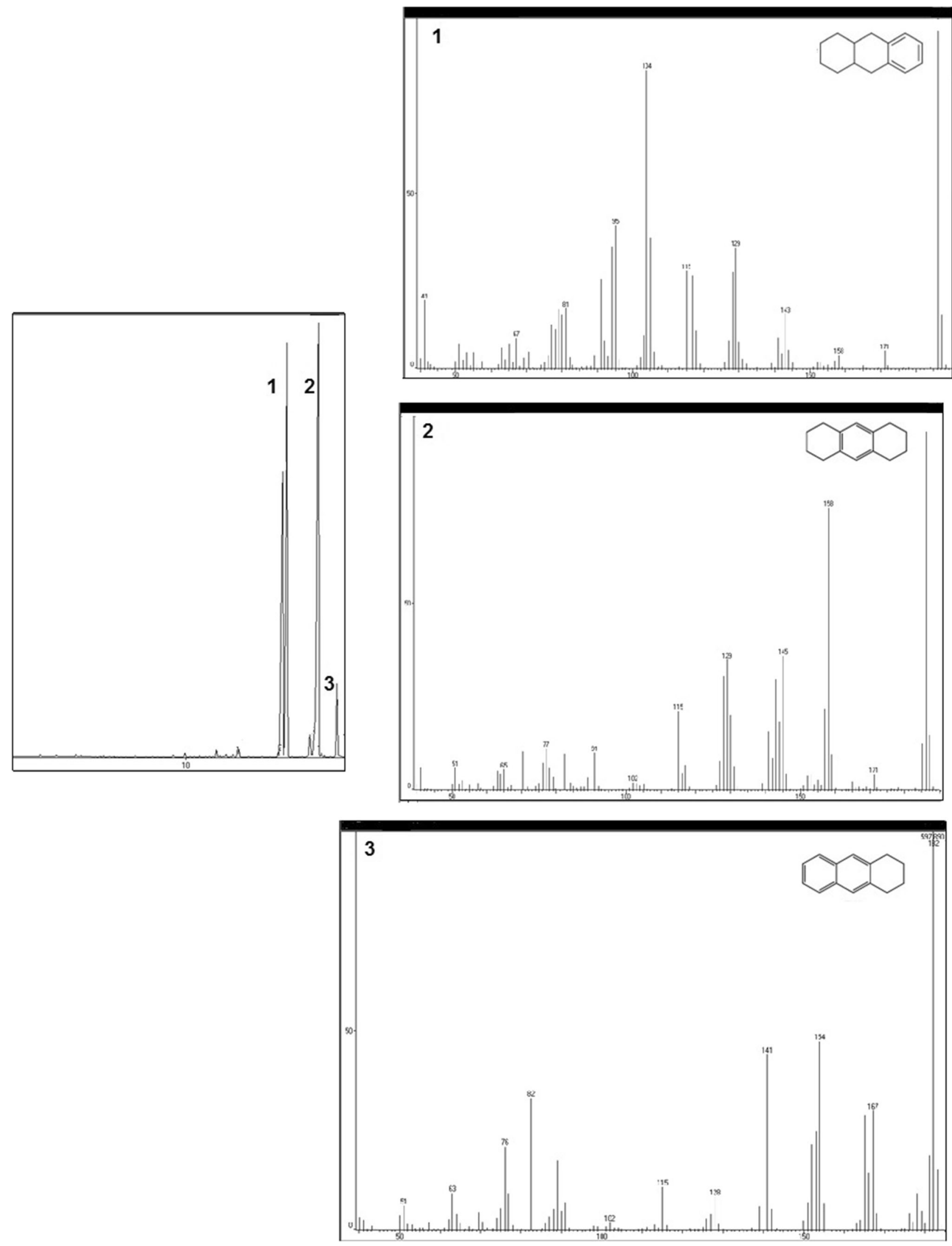


4Fig. 9 GC-MS chromatogram and the corresponding mass spectra of the main peaks (1-3) for the reduction of anthracene using the $\mathrm{Fe}_{3} \mathrm{O}_{4} @ \mathrm{mSiO}_{2} @ \mathrm{Pd}$ catalyst

were obtained by measuring ultraviolet absorption spectra of anthracene at $375 \mathrm{~nm}$. The initial chosen concentration of anthracene solutions was $18 \mathrm{ppm}$ which is well linearly related to absorbance according to our calibration curve. Figure 6 shows the hydrogenation percentage of the substrate as a function of temperature for the three catalysts. It is possible to note that at $30{ }^{\circ} \mathrm{C}$ the materials $\mathrm{Fe}_{3} \mathrm{O}_{4} @$ $\mathrm{SiO}_{2} @ \mathrm{PtPd}$ and $\mathrm{Fe}_{3} \mathrm{O}_{4} @ \mathrm{SiO}_{2} @ \mathrm{Pt}$ are very active in the hydrogenation of anthracene and both catalysts are able to remove more than $60 \%$ of the substrate into the hydrogenated counterparts in less than $20 \mathrm{~min}$. The PtPdbimetallic catalyst stands out as yielding higher substrate conversion (88\%) compared to the Pt monometallic $(67 \%)$. Even though the substrate conversion for the Pdmonometallic is not as high compared to Pt- and PtPdcatalysts the solid is also active and it is able to convert $30 \%$ of the substrate at $30{ }^{\circ} \mathrm{C}$. At $45^{\circ} \mathrm{C}$ a similar activity profile is observed and the order of activity is the same as the observed at $30{ }^{\circ} \mathrm{C}$. At $75^{\circ} \mathrm{C}$ maximum substrate removal was obtained $(>95 \%)$ for all catalysts. The enhanced activity observed for the bimetallic catalyst compared to the monometallic catalysts suggests the presence of synergistic effects when both metals are present as a random alloy structure.

Figure 7 shows the influence of pressure in the hydrogenation reaction rates. Raising the pressure from 2 to 5 bar led to a significant increase in the substrate removal. However, there is no appreciable difference as the pressure is raised above 5 bar. This suggests that at higher pressures the reaction is limited by the gas diffusion which indicates that at 5 bar the metal nanoparticles surface are already saturated by $\mathrm{H}_{2}$ molecules (Fonseca et al. 2006). The pressure study also indicates a superior activity for Pt- and PtPd-catalysts compared to Pd-catalysts. At 6 bar for instance conversions obtained for PtPd-, Pt- and Pd-catalysts are 98, 87 and 29\%, respectively. If monometallic activities were taken into account solely, we would expect a linear substrate conversion of $58 \%$ for PtPd-catalyst. The far higher anthracene removal for the hybrid PdPt-material (98\%) confirms the synergistic effects of combining the $\mathrm{Pt}$ and $\mathrm{Pd}$ in a bimetallic nanoalloy.

We also investigated the possibility of recycling a single portion of the catalyst in different runs. For this purpose, the catalysts were tested under the following established conditions: 6 atm of $\mathrm{H}_{2}, 75^{\circ} \mathrm{C}, 20 \mathrm{~min}$. Hydrogenation procedures were the same described in "Catalytic studies". However, after removing the liquid phase assisted by magnetic separation, the catalyst was dried for $5 \mathrm{~min}$ at $75{ }^{\circ} \mathrm{C}$ under vacuum using a rotary pump attached to the reactor. Then, another liquid sample containing anthracene was added to the reactor and submitted to a new reaction batch. The catalytic portions were recycled in successive runs until they lost their activity towards anthracene removal (determined by UV-Vis).

Figure 8 shows the catalysts activities achieved for each run during the recycling study. A single portion of the Ptmonometallic catalyst could be reutilized up to five times yielding substrate conversion higher than $95 \%$ for all runs. The catalytic substrate removal drops sharply on the 6th run and the conversion is as low as $28 \%$. The monometallic Pdmaterial could be used up to six times in the substrate hydrogenation; however, the substrate conversion was lower compared to that achieved with Pt-monometallic catalyst, and after the first run the maximum activity achieved for substrate removal was $80 \%$ for the 5 th run. The PtPdbimetallic solid showed the highest performance in the recycling study, and a single portion of the catalyst could be utilized up to 11 times with substrate removal higher than $90 \%$. It is worth mentioning that a significant increase of catalytic activity was observed after the 7 th run. One possible explanation for this is the reduction of residual complexed species (APTES-Pt ${ }^{2+}$ and APTES-Pd ${ }^{2+}$ ), as detected by XPS, which leads to the introduction of new active metal sites into the mesoporous magnetic support. A similar behavior was observed during the recycling of the monometallic Pd-catalyst that also displayed an increase in the catalytic activity after the 3 rd run. The enhanced performance of the bimetallic catalyst compared to the monometallic counterparts confirms the synergistic effect gained by combining Pt and Pd in a bimetallic structure. It is worth mentioning that not only does the PtPd-catalyst show a higher activity toward the substrate removal, but it also shows an enhanced catalyst durability which is twice as high as the monometallic Pt- and Pd-solids. The catalyst durability, activity and the mild reaction conditions used in the catalyzed reactions are considered prominent when compared to other Pt- Pd-based catalysts that have been reported for the conversion of PAHs into less toxic compounds by catalytic hydrogenation.

We also performed the hydrogenation experiments at higher substrate concentration in order to characterize and quantify the liquid phase containing the products by $\mathrm{GC}-$ MS. Figure 9 shows a typical GC-MS chromatogram obtained of the products detected by the GC-MS mass spectral library and the corresponding mass spectra of the main peaks. The main component cis-trans OHA has a molecular mass of $182 \mathrm{~g} \mathrm{~mol}^{-1}$. In addition, a series of two other fragmentation peaks at $m / z, 186$ and 182 corresponding to the formation of Sym-OHA and THA are also present.

The reaction conditions, products and selectivity are given in Table 1. GC-MS experiments show the presence 
of four partial hydrogenated products in the liquid phase: tetrahydro anthracene (THA), sym-1,2,3,4,5,6,7,8-octahydroanthracene (SYM-OHA), cis-,trans-1,2,3,4,4a,9,9a,10octahydroanthracene (cis-trans-OHA), and 9,10-hydroanthracene (DHA). It is worth mentioning that the three catalysts have different selectivities towards the partial hydrogenated products. Pt-monometallic catalyst is highly selective to THA while Pd-monometallic catalyst has higher selectivity to Stm-OHA and cis-trans OHA. Interestingly the PtPd-bimetallic nanoalloy clusters give rise to high selectivity to DHA which is not appreciably observed for the monometallic materials.

The proposed reaction pathway for anthracene hydrogenation using monometallic Pt-, Pd- and bimetallic PtPdcatalysts involves the initial partial hydrogenation of the substrate to DHA and THA. It has been reported that THA could also be formed by isomeric equilibria with DHA in liquid phase (fuel) (Pinilla et al. 2014). The monometallic Pt catalyst shows a high selectivity toward the formation of THA (90\%) when compared to DHA (3\%) and that suggests that under the conditions applied DHA is not formed appreciably by either a direct catalytic hydrogenation or isomeric equilibria with THA. Another strong factor that supports THA selectivity is the low concentration of SYMOHA and cis-trans OHA which could be formed by the reduction of THA and DHA forms. The products obtained using the bimetallic catalyst are THA and DHA, exclusively. The formation of DHA is probably due to the catalytic selectivity achieved combining the two monometallic phases in a bimetallic arrangement since the liquid phases have been submitted to the same conditions (temperature, $\mathrm{H}_{2}$ pressure and substrate concentration) in all catalyzed reactions. Therefore, the absence of SYM-OHA and cis-trans OHA and the low concentration of DHA form for the monometallic Pt-catalyzed reaction suggests that the considerably higher concentration of DHA achieved using the bimetallic catalyst is based on the catalytic selectivity of the material rather than a mere conversion promoted by isomeric equilibria. A similar reaction mechanism is proposed for the Pd-monometallic catalyst, but in this case it is very difficult to predict how reaction proceeds quantitatively in terms of DHA and THA formation due to its high selectivity to SYM-OHA and cis-trans OHA forms. However, based on the fact that the presence of palladium leads to a higher concentration of DHA form in the bimetallic solid, we believe that SYM-OHA and cis-trans OHA are formed by hydrogenation of both DHA and THA.

The magnetic property of the support facilitated the catalyst separation after the hydrogenation experiments. Figure 10 shows a post-reaction liquid sample containing the spent catalyst and the products dispersed in ethyl acetate. As it can be seen, the catalysts are promptly isolated by placing a small magnet on the vial wall and no extra separation methods are needed which greatly simplifies the workup procedure for product isolation. The time required to obtain total catalyst separation is also relatively short and the liquid solution is completely clear after 2 min of magnetic field exposure.

\section{Conclusions}

Two new catalysts Pd- and PtPd-embedded on a mesoporous magnetic silica support have been synthesized and characterized by XPS, TEM, ICP-AES and HAADAF-MET. The catalysts were applied in the anthracene removal from liquid media via catalytic hydrogenation under mild conditions (6 atm, $75^{\circ} \mathrm{C}, 20 \mathrm{~min}$ ). The bimetallic solid exhibited the highest durability, and a single portion of the material could be used in 11 successive runs without compromising its catalytic activity. Compared to the monometallic Pt- and Pdsolids the bimetallic PtPd-catalyst also showed higher selectivity towards the formation of partial hydrogenated DHA product. The increased catalytic activity and

Table 1 Products obtained for anthracene hydrogenation

\begin{tabular}{|c|c|c|c|c|}
\hline Catalyst & THA & Sym-OHA & cis-trans OHA & DHA \\
\hline $\mathrm{Fe}_{3} \mathrm{O}_{4} @ \mathrm{mSiO}_{2} \mathrm{Pd}$ & $3,6 \%$ & $41,7 \%$ & $54,7 \%$ & $\mathrm{ND}^{\mathrm{a}}$ \\
\hline $\mathrm{Fe}_{3} \mathrm{O}_{4} @ \mathrm{mSiO}_{2} \mathrm{PtPd}$ & $45,9 \%$ & ND & ND & $54,1 \%$ \\
\hline $\mathrm{Fe}_{3} \mathrm{O}_{4} @ \mathrm{mSiO}_{2}-\mathrm{Pt}^{*}$ & $90 \%$ & $7 \%$ & ND & $3 \%$ \\
\hline
\end{tabular}

Reaction conditions: $10 \mathrm{mg}$ of anthracene in $5 \mathrm{~mL}$ of ethyl acetate, $20 \mathrm{mg}$ of catalyst, $6 \mathrm{~atm}\left(\mathrm{H}_{2}\right.$ pressure), temperature $75{ }^{\circ} \mathrm{C}$, time $24 \mathrm{~h}$ ${ }^{\mathrm{a}}$ As reported by Jacinto et al. (2016) 


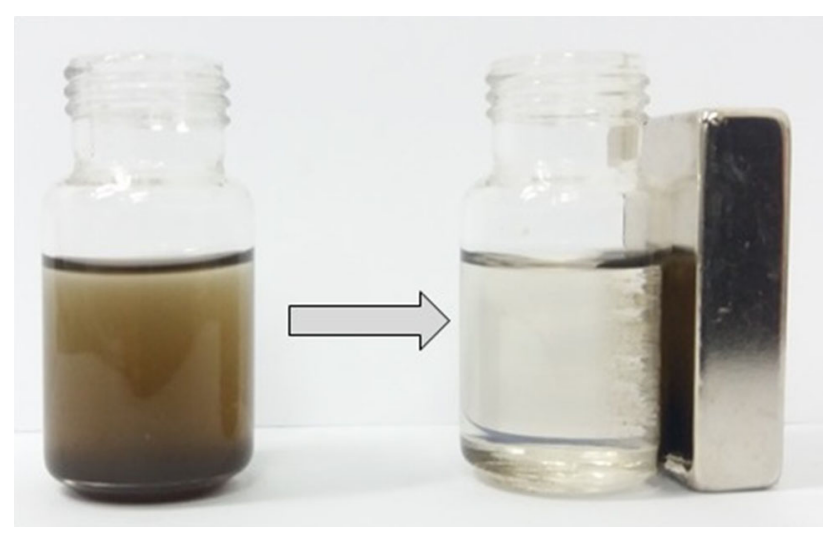

Fig. 10 Magnetic separation for the bimetallic PtPd-catalyst

distinguished selectivity to DHA can be attributed to advantageous synergistic effects that arise from combining the monometallic counterparts in a nanoalloy structure. The magnetic property of the materials was very crucial to achieve a fast product separation in an easy, convenient and effective way. The possibility of combining the magnetic separation with high active catalysts towards PAHs removal brings exciting environmental perspectives to deal with this class of environmental pollutants.

Acknowledgements The authors are grateful to Fundação de Amparo a Pesquisa do Estado do Mato Grosso (FAPEMAT), Conselho Nacional de Desenvolvimento Científico e Tecnológico (CNPq) for scholarships and financial support, and indebted to LEFE (Brazil), LME-DEMA (Brazil) and LMC-UNB for the XPS, TEM and BET analysis, respectively.

Open Access This article is distributed under the terms of the Creative Commons Attribution 4.0 International License (http:// creativecommons.org/licenses/by/4.0/), which permits unrestricted use, distribution, and reproduction in any medium, provided you give appropriate credit to the original author(s) and the source, provide a link to the Creative Commons license, and indicate if changes were made.

\section{References}

Atchudan R, Pandurangan A (2012) The use of bimetallic MCM-41 mesoporous catalysts for the synthesis of MWCNTs by chemical vapor deposition. J Mol Catal A Chem 355:75-84

Dash P, Dehm NA, Scott RWJ (2008) Bimetallic PdAu nanoparticles as hydrogenation catalysts in imidazolium ionic liquids. J Mol Catal A Chem 286:114-119

Fei S, Xia K, Tian X, Mei P, Yan H, Cheng H (2016) Fabrication of ordered mesoporous $\mathrm{MoO}_{3}$ for olefin catalytic hydrogenation. Int J Hydrogen Energy 41:5652-5660

Fonseca GS, Domingos JB, Nome F, Dupont J (2006) On the kinetics of iridium nanoparticles formation in ionic liquids and olefin hydrogenation. J Mol Catal A Chem 248:10-16

Gregg SJ, Sing KSW (1982) Adsorption, surface area and porosity. Ber Bunsen Ges Phys Chem 86:957

IARC International Agency for Research on Cancer (1983) Lyon, França. https://monographs.iarc.fr. Accessed $10 \mathrm{dez} 2016$
Jacinto MJ, Kiyohara PK, Masunaga SH, Jardim RF, Rossi LM (2008) Recoverable rhodium nanoparticles: synthesis, characterization and catalytic performance in hydrogenation reactions. Appl Catal A 338:52-57

Jacinto MJ, Wizbiki M, Justino LC, Silva VC (2016) Platinumsupported mesoporous silica of facile recovery as a catalyst for hydrogenation of polyaromatic hydrocarbons under ultra-mild conditions. J Sol Gel Sci Technol 77:298-305

Li G, Liu Y, Du H (2015) B $\left(\mathrm{C}_{6} \mathrm{~F}_{5}\right)_{3}$-catalyzed metal-free hydrogenation of naphthylamines. Org Biomol Chem 13:2875-2878

Liao W, Liu HW, Chen HJ, Chang WY, Chiu KH, Wai CM (2011) Catalytic hydrogenation rate of polycyclic aromatic hydrocarbons in supercritical carbon dioxide containing polymer-stabilized palladium nanoparticles. Chemosphere 82:573-580

Nador F, Moglie Y, Vitale C, Yus M, Alonso F, Radivoy G (2010) Reduction of polycyclic aromatic hydrocarbons promoted by cobalt or manganese nanoparticles. Tetrahedron 66:4318-4325

Neff JM (2002) Bioaccumulation in marine organisms: effect of contaminants from oil well. Elsevier, New York

Park J, Na K, Hwang Y, Park J-G, Noh H-J, Kim J-Y, Park J-H, Hwang H-M (2004) Ultra-large-scale syntheses of monodisperse nanocrystals. Nat Mater 3:891-895

Pinilla JL, García AB, Philippot K, Lara P, García-Suárez EJ, Millan M (2014) Carbon-supported Pd nanoparticles as catalysts for anthracene hydrogenation. Fuel 116:729-735

Rengarajan T, Rajendran P, Nandakuma N, Lokeshkumar B, Rajendran P, Nishigaki I (2015) Exposure to polycyclic aromatic hydrocarbons with special focus on câncer. Asian Pac J Trop Biomed 5:182-189

Srogi K (2007) Monitoring of environmental exposure to polycyclic aromatic hydrocarbons: a review. Environ Chem Lett 5:169-195

Valles VA, Ledesma BC, Rivoira LP, Cussa J, Anunziata OA, Beltramone AR (2016) Experimental design optimization of the tetralin hydrogenation over Ir-Pt-SBA-15. Catal Today 271:140-148

Villa A, Chan-Thaw CE, Campisi S, Bianchi CL, Wang D, Kotula PG, Kübel C, Prati L (2015) AuRu/AC as an effective catalyst for hydrogenation reactions. Phys Chem Chem Phys 17:28171-28176

Wagner CD, Riggs WM, Davis LE, Moulder JF, Muilenberg GE (1979) Handbook of X-ray photoelectron spectroscopy. Eden Prairie, Minnesota

Wang Z, Yang L, Zhang R, Li L, Cheng Z, Zhou Z (2016) Selective hydrogenation of phenylacetylene over bimetallic $\mathrm{Pd}-\mathrm{Cu} / \mathrm{Al}_{2} \mathrm{O}_{3}$ and $\mathrm{Pd}-\mathrm{Zn} / \mathrm{Al}_{2} \mathrm{O}_{3}$ catalysts. Catal Today 264:37-43

World Health Organization (2010) WHO guidelines for indoor air quality selected pollutants. WHO Regional Office for Europe, Copenhagen, Denmark

Yuan T, Marshall WD (2005) Catalytic hydrogenation of polycyclic aromatic hydrocarbons over palladium $/ \gamma-\mathrm{Al}_{2} \mathrm{O}_{3}$ under mild conditions. J Hazard Mater 126:149-157

Zhang Y, He X, Ouyang J, Yang H (2013) Palladium nanoparticles deposited on silanized halloysite nanotubes: synthesis, characterization and enhanced catalytic property. Sci Rep. 3:2948-2952

Zhang L, Zhou L, Yang K, Gao D, Huang C, Chen Y, Zhang F, Xiong X, Ling Li, Xia Q (2016) Pd_Ni nanoparticles supported on MIL-101 as high-performance catalysts for hydrogen generation from ammonia borane. J Alloys Compd 677:87-95

Ziolek M (2004) Catalytic liquid-phase oxidation in heterogeneous system as green chemistry goal-advantages and disadvantages of MCM-41 used as catalyst. Catal Today 90:145-150

\section{Publisher's Note}

Springer Nature remains neutral with regard to jurisdictional claims in published maps and institutional affiliations. 